\title{
STEAM VOLATILES OF COCONUT BARK: CHEMICAL INVESTIGA- TIONS AND ELECTROANTENNOGRAM RESPONSES OF THE COCONUT PEST, RHYNCHOPHORUS FERRUGINEUS (COLEOPTERA: CURCULIONIDAE)
}

\author{
NEELAKANTHI E. GUNAWARDENA \\ Department of Chemistry, University of Kelaniya, Kelaniya
}

(Received: 30 October 1992; accepted: 10 November 1994)

\begin{abstract}
Steam volatiles of the young coconut (Cocos nucifera) bark were analyzed by combined gas chromatography - mass spectrometry (GC-MS). Among the large number of components present were ethanone -1 (2-hydroxy5-methyl), 4-hydroxy-3-methoxybenzaldhyde, acetophenone, phenol, xylene, nonanal, decenal, diethylene glycol, nonanoic acid and $\alpha$-ionone. Electroantennogram (EAG) responses of the isolated antennae of adult male and female Rhynchophorus ferrugineus F. to the total steam distillate and its two column fractions, and the individual constituents were recorded. The total steam distillate elicited a significantly greater EAG response of $32.3 \pm 6.9$ ( $p<0.05$, ANOVA, Scheffe's test) than those of the other test stimuli. The two column fractions elicited moderate EAG responses of $19.3 \pm 1.8$ and $14.02 \pm 2.3$. Of the synthetic bark constituents tested all, except $\alpha$-ionone, elicited low EAG responses ranging from EAG 7.1 to 13.0. $\alpha$-ionone showed a moderate EAG response of $18.5 \pm 3.0$, significantly different ( $p<0.05$, ANOVA, Scheffe's test) from those of the other synthetic constituents.
\end{abstract}

Key words: Coconut bark volatiles, coconut pèst, electroantennogram assay, Rhynchophorus ferrugineus

\section{INTRODUCTION}

The detection and deciphering of chemical signals in the environment is important in determining many aspects of insect behaviour. ${ }^{1}$ Due to its potential in the management of insect pests, much effort has been devoted to this area of research. Thus, insect pheromones ${ }^{2,3}$ and plant volatiles have received more attention in recent years. Volatiles emanating from plants may serve as primary attractants to guide the insect to host plants for feeding and oviposition ${ }^{4}$ or may enhance the response of insects to their pheromones. ${ }^{3,5}$ Insect attraction to host plant volatiles has been less understood than pheromones, in particular the sex pheromones of Lepidoptera. ${ }^{2}$

The complex host finding behaviour of coleopterans has been subjected to much study ${ }^{6}$ and a number of host plant volatiles that attract coleopterans have recently been chemically characterized. ${ }^{7,8}$ Many such attractants are simple alcohols, chiral alcohols, simple acetates, aldehydes or terpenes. For example bark beetles (Scolytidae) respond primarily to terpenes from pine., ${ }^{2,6}$ The Boll weevil, Anthonomus grandis Boh. (Curculionidae) is attracted to the host volatiles $\beta$-caryophyllene, trans-2-hexen-1-ol, trans- $\beta$ - ocimene, benzaldehyde, linalool and $\beta$-bisabolol. ${ }^{7}$ For chemically mediated food finding in Glischrochilus quadrisignatus Say (Nitidulidae) a four component mixture composed of ethyl acetate, acetaldehyde, ethanol and racemic 2-methylbutanol, appears necessary 
with the first three components being essential. In the case of $G$. fasciatus Olivier ethyl acetate and ethanol were the essential components for attraction. ${ }^{8}$ For the dung beetle Pachylomerus femoralis Kirby in the fruit of the spineless monkey orange tree, Strychnos madagascariensis has a multicomponent attractant composed of 1-butanol, methyl butanoate, ethyl 2-methyl propanoate, ethylbutanoate, butyl 2-methylpropanoate, butyl ethanoate, ethyl 2methylbutanoate, propyl butanoate, butyl propanoate, methyl hexanoate and butyl butanoate. ${ }^{9}$

Few studies have been devoted to the chemical ecology of Rhynchophorus (Colooptera: Curculionidae) species despite their economic impact. The American palm weevil, $R$. palmarum, L. is a major pest on coconut and oil palm crops in tropical America and the West Indies has been recently studied and an artificial bait formulated to trap this pest, although the basis for the formulation is not clear from the report. ${ }^{10}$ More recently, a male mediated aggregation pheromone of this weevil has also been identified. ${ }^{11}$

Rhynchophorus ferrugineus, F. commonly known as the red weevil, is one of the five major pests on coconut in Sri Lanka ${ }^{12}$ whose attacks cause heavy damage leading to the eventual death of palms. The larva of this pest lives entirely on the tissue of the palm where it excavates galleries causing great damage to the tree. Present control methods involving insecticides pose a danger to the applicant as well as to the environment. ${ }^{13}$ This pest was shown to be highly attracted to host volatiles in a behavioural bioassay. ${ }^{14}$ Investigations on the chemical constituents of the volatiles, may lead to the development of an artificial bait for this pest, which is hard to observe and difficult to control in the field. The chemical identification of some of the constituents in the steam wolatiles of coconut bark, and the electrophysiological activity of their synthetic equivalents with $R$. ferrugineus are reported here.

\section{METHODS AND MATERIALS}

Sieam volatiles and fractionation: Young coconut bark was cut into small pieces and was steam distilled for $5 \mathrm{~h}$. The aqueous layer was saturated with $\mathrm{NaCl}$ and was extracted with diethyl ether (Analar grade, $\mathrm{BDH}, \mathrm{UK}$ ). Next, the ether layer was dried over $\mathrm{MgSO}_{4}$ and the solvent was allowed to evaporate until a concentrated solution resulted. A portion of this solution was fractionated on preparative (TLC) silica gel plates $(20 \mathrm{~cm} \times 20 \mathrm{~cm})$ with the developing solvent system, petroleum ether: methylene chloride (3:1). As determined by our previous behavioural assay, ${ }^{14}$ only the fractions having $R_{\mathrm{f}}$ values 0.31 and 0.40 were used in the electroantennogram (EAG) assay.

Chemical analysis: Gas chromatography - mass spectrometry (GC-MS) was performed on Finigan MAT 90 GC-MS, on a glass column $(25 \mathrm{~m})$ coated with the stationary phase (SE-52), with a temperature programme, 4 min at $60^{\circ} \mathrm{C}$, from $60^{\circ} \mathrm{C}$ to $260^{\circ} \mathrm{C}$ at $6^{\circ} \mathrm{C} / \mathrm{min}$, carrier gas $\mathrm{He}, 2 \mathrm{sec} / \mathrm{scan}, 70 \mathrm{eV}$, EI mode, splitless injection. 
Chemicals and preparation of solutions for EAG assay: The solvent hexane (Analar grade) was purchased from Merck, Germany. Ethanone, 1-(2-hydroxy5-methyl), 4-hydroxy, 3-methyl benzaldehyde, ethanone, 1-phenyl (acetophenone), phenol, xylene, nonanal, nonanoic acid and diethylene glycol were purchased from Aldrich, Germany. $\alpha$-Ionone was purchased from Haarmann and Reimer, Germany. 2-Decenal, 2-(Z)-nonenal, 2-(Z)-nonenol were synthesized in the laboratory and the purity was established to be $99 \%$ by GLC analysis. For EAG assay the sample size of a stimulus was $1 \mu \mathrm{g}$. Stock solutions of the synthetic compounds were prepared by first dissolving appropriate amounts of the compounds in hexane to give $10 \mathrm{mg} / \mathrm{ml}$ solutions. From this $1 \mu \mathrm{l}$ was withdrawn and mixed with $99 \mu \mathrm{l}$ of pure hexane. A $10 \mu \mathrm{l}$ portion of the diluted solution was put onto filter paper strip (see later) and the solvent allowed to evaporate. In the case of steam distillate and the column fractions, concentrated ether solutions were diluted by mixing $1 \mu \mathrm{l}$ of the concentrate with $99 \mu \mathrm{l}$ of hexane and $10 \mu \mathrm{l}$ of this solution was used on filter paper strip. This was placed in a cartridge after evaporation of the solvent.

EAG assay of the potential stimulants: Adult weevils were field collected and shipped from Sri Lanka to Germany by air. They were fed with apple and water and kept in a room where the temperature was maintained at $30^{\circ} \mathrm{C}$. For EAG assay a weevil was anaesthetized with a stream of $\mathrm{CO}_{2}$ and the antenna was cut as close as possible to the base. Following the methodology of recording EAG described by Arn et al. ${ }^{15}$ the antenna was fixed on two Ag-AgCl electrodes which were placed in glass capillary tubes filled with insect Ringer's solution. ${ }^{16}$ The recording electrode was inserted into the club of the antenna and the indifferent electrode to the base of the antenna. In order to prevent leakage of receptor lymph and the subsequent drying up of the antenna, both ends of the antenna were sealed with vaseline. Total time of mounting did not exceed $10 \mathrm{~min}$. Odour stimulation was performed by purging a-stream of filtered air through the cartridge loaded with test substance for a period of $1 \mathrm{sec}$. A vacuum outlet was already positioned approximately $10 \mathrm{~cm}$ behind the setting of the antenna in order to remove attractant containing air from the area surrounding the antenna. A stream of filtered air $(0.5 \mathrm{l} / \mathrm{min})$ continuously bathed the antenna, except at the time that the stimuli was applied. The responses of the antenna to test stimulants were recorded as peaks and the distance between the base and the highest point of the peak were measured. The entire series of test compounds were presented to each antenna on a random basis and each test compound was presented to 4 male and 4 female antennae. The EAG response of $R$. ferrugineus to the control (hexane $10 \mu \mathrm{l}$ ) was used as the internal standard. Interspersed between every fifth test stimulation, the control stimulation was offered continuously throughout the experiment and the corrections for individual and time dependent alterations in responses were made. All comparisons of mean EAG responses of $R$. ferrugineus were done by the use of ANOVA Scheffe's test, unless otherwise stated. 


\section{RESULTS}

\section{Chemical analysis of the steam distillate}

Gas chromatogram of the steam distillate showed more than 100 peaks some of which were identified by mass spectral data.

$\mathrm{m} / \mathrm{z}$; Diethyleneglycol : $106(2 \%), 76(10 \%), 75(25 \%), 45(100 \%), 44(10 \%), 43(12 \%)$.

Phenol:

Acetophenone:

(ethanone 1-phenyl)

Xylene:

Nonanal:

2-(Z)Nonenal:

2(Z)-Nonenol:
94(100\%), 81(10\%), 66(30\%), 55(10\%), 39(22\%).

120(24\%), 105(100\%), 77(76\%), 51(22\%), 43(15\%).

106(90\%), 105(88\%), 77(100\%), 51(58\%), 50(35\%).

142(5\%), 127(7\%), 98(35\%), 96(30\%), 82(38\%), 70(35\%), 57(60\%), 43(100\%).

$140(0.5 \%), 124(5 \%), 12(2 \%), 122(8 \%), 107(12 \%), 96(20 \%)$, 93(48\%), 81(46\%), 79(44\%), 67(98\%), 55(80\%), 41(100\%).

$140(0.5 \%), 124(8 \%), 109(22 \%), 98(30 \%), 82(35 \%), 68(38 \%)$, 57(94\%), 41(100\%).

Ethanone:

1(2-hydroxy-5-methyl) 150(100\%), 135(90\%), 107(78\%),77(66\%), 51(24\%), 39(18\%).

4-Hydroxy-3-methoxybenzaldehyde:

152(100\%), 151(99\%), 136(12\%), 123(12\%), 109(24\%), 81(40\%), 65(18\%), 51(20\%).

2-Decanal:

154(1\%), 153(1.5\%), 144(8\%), 129(15\%), 109(10\%), 95(14\%), 83(38\%), 70(45\%), 55(60\%), 43(100\%).

Nonanoic acid:

$.158(10 \%), 129(20 \%), 115(25 \%), 101(10 \%), 98(15 \%)$.

Decanoic acid: $\quad 172(15 \%), 149(10 \%), 129(50 \%), 112(12 \%), 87(18 \%)$, 73(100\%), 60(100\%).

$\alpha$-Ionone:

192(30\%), 136(50\%), 121(100\%), 93(75\%), 77(25\%), 55(10\%), 43(70\%).

Dodecanoic acid: $\quad 200(30 \%), 171(10 \%), 157(20 \%), 129(34 \%) ; 85(22 \%)$, 73(100\%), 60(96\%), 55(62\%), 43(80\%). 


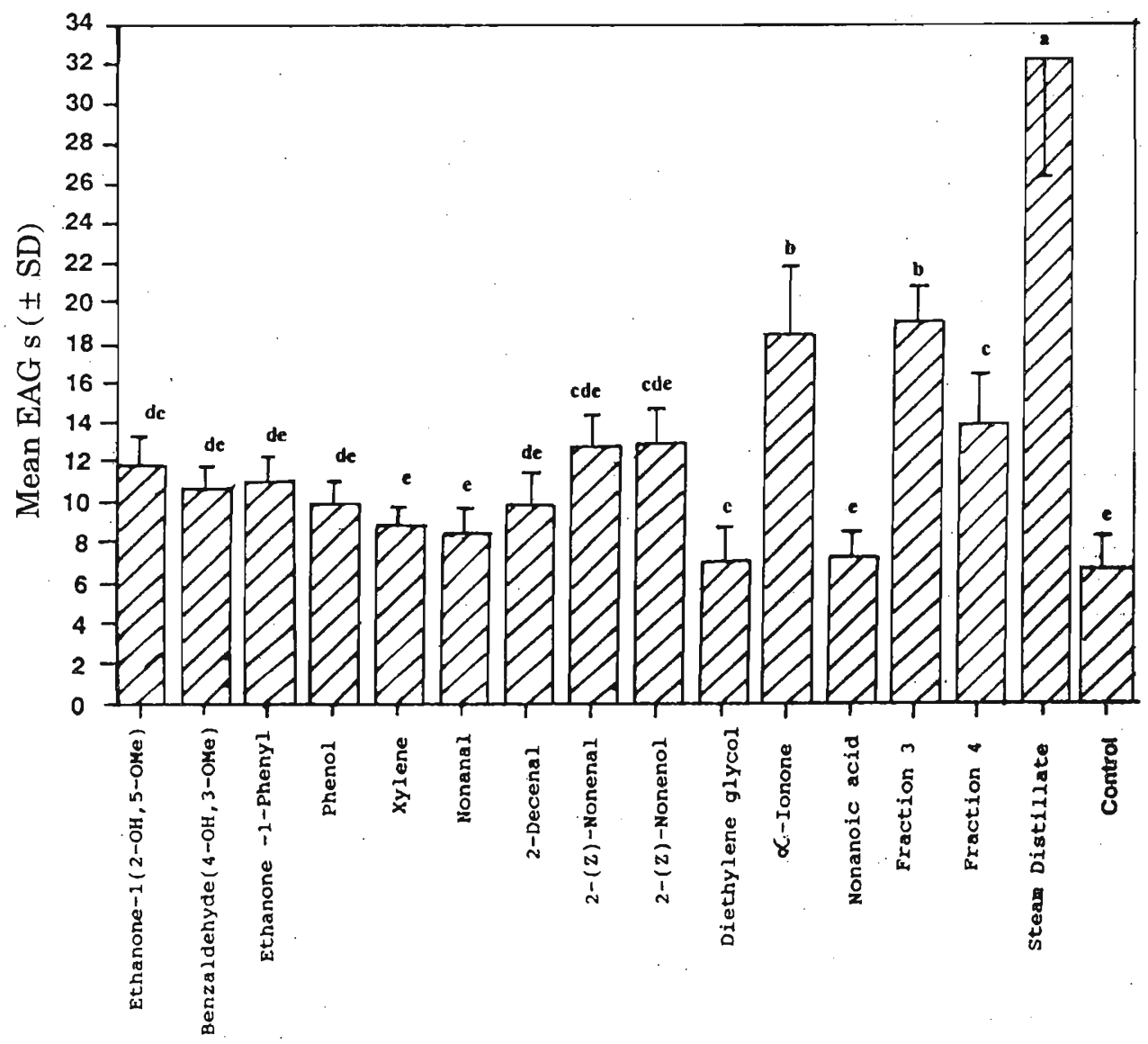

Test substances $(1 \mu \mathrm{g})$

Figure 1: Mean electroantennogram responses ( \pm SD) of $R$. ferrugineus to coconut bark steam volatiles*, two of the column fractions* and some of the constituents (synthetic equivalents). Bars marked by the same small letters (a-e) are not significantly different $(p<0.05)$, ANOVA, Scheffe's test.

* stimulus $=10 \mu \mathrm{l}$ of an ether solution was used.

\section{EAG assay of the synthetic chemicals}

The mean EAG responses of male and female red weevil for the hexane control did not differ significantly ( $p>0.05$, Student's t-test) (EAGs $=30.4, \pm 8.4$ and $30.8 \pm 6.1$ respectively) and therefore the data were pooled in the calculation of the means. 
EAG responses of the weevil antenna to test stimuli (Fig. 1) indicated highest activity for the total steam distillate with a mean \pm SD EAG amplitude of $32.3 \pm 6.9$, significantly different $(p<0.05)$ from those of the other stimuli. Lower activities were elicited by fraction 3 EAG $(19.3 \pm 1.8)$ and a lesser activity by fraction 4 EAG $(14.0 \pm 2.3)$. Other test stimuli except $\alpha$-ionone showed even lower EAG activities with means ranging from 7.1 to 13.0 . $\alpha$-Ionone had a moderate EAG activity $(18.5 \pm 3)$ not significantly different $(\mathrm{p}>0.05)$ from that of fraction 3.

\section{DISCUSSION}

Only limitedinformation is available on the chemistry of the volatiles from palm trees. Volatiłes of the crade palm oil were reported to include simple alkanals (C-5, C-6, C-9), alkenals (C-7, C-8, C-10, C-11), dialkenals (C-7, C-10), xylene, benzaldehyde, $\beta$ - ionone, $\alpha$-ionone, $\alpha$ - terpineol, sesquiterpene hydrocarbon (unidentified) and oxygenated monoterpenes as major constituents. ${ }^{17}$ Steam volatiles of coconut bark were similar because they contained simple alkanals (C-9), alkenals (C-9, C-10), and simple aromatics such as xylene, acetophenone, $\alpha$-Ionone and an unidentified sesquiterpene. In addition we found diethylene glycol, and some phenolic compounds among the constituents identified. However a large number of constituents could not be identified.

The multicomponent nature of host attractants is a well established phenomenon. ${ }^{8,9}$ Hence, combined gas . chromatography- electroantennography (GC-EAG) technique is more effective for identifying the active constituents in the bark volatiles. The attempts to carry out GC-EAG were unsuccessful because of the high noise levels compared to signals. The EAG assay of the constituents (synthetic equivalents) of the steam distillate elicited only low responses in the antennal receptors of the red weevil compared to that of the natural attractant.

In the family Curculionidae terpenes are strong candidates as attractants. For example, Anthonomus grandis is attracted to several terpenesviz. $\beta$ caryophyllene, $\beta$-bisabolol trans- $\beta$-ocimene in its host volatiles. ${ }^{7}$ Of all the test stimuli belonging to a range of compounds such as aromatics, aliphatic saturated \& unsaturated long chain aldehydes alcohols etc. only the terpene elicited a high response. It is possible that terpenes are potent attractants for $R$. ferrugineus also. However the much higher mean EAG value of the natural attractant (total steam volatiles) suggests the presence of other attractants in the host volatiles or synergism between constituents. Synergism however cannot be estimated by EAG experiments and therefore a proper behavioural bioassay is needed to test this phenomena.

From the reported data of the host attractants of coleopterans it is understood that active components include short-chain compounds ${ }^{8}$ such as ethyl acetate, acetaldehyde, ethanol etc. None of the above compounds were detected in our analysis. A head space analysis of the coconut bark would trap all the volatiles better and this would provide more information on the attractants. The attraction of $R$. ferrugineus to simple alcohols was already shown by our. behavioural bioassay. ${ }^{14}$ 
Further work is still necessary to complete this investigation. Combined gas liquid chromatography - electroantennographic GC-EAG analysis of the coconut steam bark distillate and a head space analysis would be more fruitful.

\section{Acknowledgement}

A research grant from the International Foundation for Science, Sweden (F/936-2), a fellowship from the Alexander von Humboldt Foundation and help from Professor H.J.Bestmann, and Mr.F.Kern of the Institute of Organic Chemistry, University of Erlangen - Nürnberg, Germany with the EAG technique are acknowledged.

\section{References}

1. Bell W. J. \& Carde R.T. (1984). Chemical ecology of insects-ii pp. 524. Sunderland, Sinauer Associates. Massachusetts.

2. Carde R.T. \& Baker T.C. (1984). Sexual communication with sex pheromones In Chemical Ecology of Insects (Eds. W.J. Bell and R.T. Carde). pp. 355-383. Sunderland Sinauer Associates, Massachusetts.

3. Birch M.C. (1984). Aggregation in bark beetles. ibid. pp. 331-353.

4. Miller J. R. \& Sticker K. L. (1984). Finding and accepting host plants, ibid. pp. 127-157.

5. Dickens J. C. (1989): Green leaf volatiles enhance aggregation pheromone of boll weevil, Anthonomus grandis. Entomologia Experimentalis Applicata 52: 191-203.

6. Vitae J. P. \& Franke W. (1976). The aggregation pheromones of bark beetles: progress and problems. Naturwissenschaften 63: 550-555.

7. Dickens J. C. (1990). Specialized receptor neurons for pheromones and host plant odors in the boll weevil, Anthonomus grandis Boh. (Coleoptera: Curculionidae). Chemical Senses 15(3): 311-331.

8. Lin H. \& Phelan P. L. ( 1991). Identification of food volatiles attractive to Glischrochilus quadrisignatus and G. faciatus (Coleoptera: Nitidulidae). Journal of Chemical Ecology 17(12): 2469-2480

9. Burger B.V.\& Petersen W.G.B. (1991). Semiochemicals of the Scarabaeinae, III:Identification of the attractant for the dung beetle Pachylomerus femoralis in the fruit of the spineless monkey orange tree, Strychnos madagascariensis Zeitschrift fur Naturforschung 46c: 1073-1079. 
10. Hagley E.A.C. (1965). Tests of attractants for the palm weevil. Journal of Economic Entomology 58(3): 1002-1003.

11. Rochard D., Malosse C., Lettere M., Ducrot P., Zagatti P., Renou M. \& Descoins C. (1991). Male produced aggregation pheromone of the American palm weevil, Rhyncophorus palmarum (L), (Coleoptera, Curculionidae): collection, identification, electrophysiological activity and laboratory bioassay. Journal of Chemical Ecology 17(11): 2127-2141.

12. Pinto J. L. J. G. (1984). Red weevil. Coconut Bulletin 1(2): 36-37.

13. Estate management and pest control. Advisory Leaflet No.37 and 50. Coconut Research Institute, Lunuwila, Sri Lanka.

14. Gunawardena N.E. \& Gunatilake R. (1993). Preliminary studies on a host attractant of th e coconut pest, Rhynchophorus ferrugineus (Coleoptera: Curculionidae). Journal of the National Science Council of Sri Lanka 21(1): 93-101.

15. Arn H., Stadler E. \& Rauscher S. (1975). The electroantennographic detector: a selective and sensitive tool in the gas chromatographic analysis of insect pheromones. Zeitschrift fur Naturforschung 30c: 722-725.

16. Barbosa P. (1974). Manual of basic techniques in insect histology. Autumn Publishers, Amherst, Massachusetts. pp. 240.

17. Dirinck P., Schreyen L., Schoenmacker F., Wychuyse F. \& Schamp N. (1977). Volatile components of crude palm oil. Journal of Food Science 42(3): 645-648. 